QUADERNS DE FILOSOFIA VOL. VII NÚM. I (2020): 8 I

eISSN: 234I-3042 DOI: I O.7203/QFIA. 7.I.I7777

\title{
Un record de Vicent Baggetto i Torres
}

Heus ací unes paraules per recordar i homenatjar a l'amic i company, de tants anys, Vicent Baggetto.

Vicent ens va deixar el proppassat 23 de gener. Tenia 65 anys. Dolorosa pèrdua per a molts de nosaltres. Malgrat tenir un currículum ben llarg, els membres de la Societat de Filosofia del País Valencià que hem compartit amb ell tantes coses, percudits com estem en la fibra emocional per la seua mort, no serem capaços, ni molt menys, d'escriure tantes fites institucionals com li pertoquen. Va ser catedràtic de filosofia i director durant 26 anys de l'Institut d'Ensenyament Secundari Joan Fuster de Sueca, i també vicepresident del Consell Escolar de la Generalitat Valenciana fins el mateix dia del seu traspàs. L'educació valenciana en valencià ha perfilat estructuralment tota la vida professional de Vicent Baggetto. La seua militància activa en el Bloc Nacionalista del País Valencià el portà també a fer-se càrrec, com a membre, de la comissió sectorial d'Educació de Compromís, etc., etc.

De tantes vivències compartides amb ell, en recorde algunes per l'empremta especial que em varen deixar. En el 2003 va morir Josep Lluís Blasco Estellés, president de la Societat de Filosofia del País Valencià, que havia descobert Vicent en els primers anys noranta i l'havia nomenat secretari de la Societat. La seua tasca com a secretari també es va fer estructural perquè després del professor Blasco jo mateix vaig ser nomenat president de la Societat i la importància i bones maneres de Vicent varen fer que seguírem junts, ell com a secretari i jo com a president, fins el 2013. Em ve al cap també l'edició el 2004 de La nau del coneixement de Josep Lluís Blasco, a càrrec de Jesús Alcolea i Xavier Serra; Vicent Baggetto es va implicar de debò en les faenes de tria i edició de l'obra que recollia un conjunt dels millors articles del seu amic J. L. Blasco.

Incloent aquestes paraules en la nostra revista Quaderns de filosofia quedarà enregistrada la gratitud que li devem al nostre amic Vicent. 